\title{
APLIKASI EDUKASI BUDAYA TOBA SAMOSIR BERBASIS ANDROID
}

\author{
Harni Kusniyati ${ }^{1}$, Nicky Saputra Pangondian Sitanggang ${ }^{2}$ \\ 1,2Program Studi Informatika, Fakultas Ilmu Komputer \\ Universitas Mercu Buana \\ 1'harni246@gmail.com, ${ }^{2}$ nick.saputrapangondian@gmail.com
}

\begin{abstract}
ABSTRAK
Budaya adalah suatu cara hidup yang berkembang, dan dimiliki bersama oleh sebuah kelompok orang, dan diwariskan dari generasi ke generasi. Banyak dari lapisan masyarakat sekarang ini telah menggunakan teknologi informasi dan komunikasi sebagai salah satu sektor kompetitif yang bisa menambah nilai dari proses bisnis yang dijalankan. Perkembangan teknologi informasi dan komunikasi telah menguntungkan pihak yang menggunakan yaitu menjadi sarana yang dapat mempermudah penggunanya mengakses berbagai informasi kebudayaan toba samosir melalui aplikasi edukasi budaya toba samosir berbasis android ini. Saat ini kegiatan kunjungan wisata bagi sejumlah orang ke beberapa tujuan wisata di daerah-daerah yang mempunyai tempat wisata yang unik dan menarik dapat dimudahkan dengan adanya perangkat bergerak seperti smartphone dan tablet-PC. Aplikasi Edukasi Budaya Toba Samosir ini dibuat mengguanakan bahasa pemograman java dan mengunakan basis data SQLite, serta bantuan perangkat lunak android development tools.
\end{abstract}

Kata Kunci : Budaya, Toba Samosir, Edukasi, Android

\begin{abstract}
Culture is a way of life that developed and shared by a group of people, and inherited from one generation to the next. Nowadays, many societies has been using information and communications technology as a competitive sector that can added value to the business processes that run. The development of information and communication technology make the parties benefited as facilitator to users to access a variety of cultural information through the educational applications Toba Samosir based android. Nowadays, vacations activity for a number of tourist to several unique and attractive destination can be facilitated through mobile devices such as smartphones and tablet-PCs. The application, Toba Samosir Cultural Education is created using the java programming language and uses a SQLite database, and supported by android software development tools.
\end{abstract}

Keywords: Culture, Toba Samosir, Education, Android 


\section{PENDAHULUAN}

Saat ini semakin mudahnya akses untuk mencari informasi melalui smartphone, hal ini menjadi alasan utama banyak orang yang menggunakan smartphone. Penunjang smartphone pun kini sudah sangat berkembang sangat cepat dengan bermacam-macam fungsinya. Smartphone yang saat ini peminatnya yang semakin meningkat tajam yaitu Android. Android merupakan terobosan baru dalam bidang teknologi saat kini, dengan kemudahan pemakaiannya dan bersifat open source membuat peminat dari gadget ini semakin banyak dan sudah menjadi hal yang umum. Hampir semua vendor saat ini mengembangkan produknya dengan sistem operasi Android. Mulai dari pengembangan aplikasi yang dapat diunduh dengan mudah, hingga pengembangan sistem yang beragam. Selain itu, banyaknya aplikasi-aplikasi yang memudahkan para pengguna gadget smartphone untuk berkomunikasi dan menunjang kegiatan sehari-hari telah banyak ditawarkan di Play Store, aplikasi yang menjadi pusat dari segala aplikasi Android yang dapat dipasang pada smartphone Android dengan masing-masing kelebihan dari tiap aplikasi tersebut membuat para pengguna gadget smartphone banyak menggunakannya.

Berdasarkan uraian pada latar belakang masalah, maka dirumuskan sebuah masalah yaitu :

1. Bagaimana cara untuk membuat Aplikasi Edukasi Budaya Toba-Samosir Berbasis Android yang dapat mempermudah pengguna mencari informasi tentang berbagai budaya yang ada di Toba Samosir?

2. Bagaimana cara membuat aplikasi ini menjadi mempermudah mengakses informasi budaya Toba Samosir?

3. Bagaimana cara membuat aplikasi yang mengenalkan informasi mengenai budaya, wisata dan juga kesenian khas Toba Samosir kepada user agar dapat dipahami sebelum menuju lokasi yang akan dikunjungi?

Berdasarkan rumusan masalah yang telah ditentukan, maka penulis membatasi masalah pada aplikasi ini, antara lain :

1. Aplikasi ini menggunakan bahasa pemrograman Java khusus untuk android (Eclipse) dan database MySQL sebagai database.

2. Pemrograman dari aplikasi ini dibuat dengan sederhana untuk informasi mengenai budaya yang ada di Toba Samosir.

3. Segmentasi user aplikasi ini adalah untuk wisatawan yang akan mengunjungi daerahdaerah yang ada di Indonesia.

Tujuan pembuatan aplikasi ini adalah untuk memberikan keterangan lokasi, informasi budaya daerah, gambar, dan suara alat musik khas daerah yang mengenalkan kepada user agar dapat dipahami sebelum menuju lokasi wisata yang akan dikunjungi.
Adapun manfaatnya antara lain:

1. Dapat digunakan sebagai media informasi dalam berwisata di daerah Toba Samosir.

2. Mempermudah wisatawan untuk mengetahui apa saja budaya-budaya di Toba Samosir yang berbeda-beda juga menarik dan wajib dijadikan lokasi wisata berkunjung di Indonesia.

\subsection{Pengertian Budaya}

Budaya adalah suatu cara hidup yang berkembang, dan dimiliki bersama oleh sebuah kelompok orang, dan diwariskan dari generasi ke generasi. Budaya terbentuk dari banyak unsur yang rumit, termasuk sistem agama dan politik, adat istiadat, bahasa, perkakas, pakaian, bangunan, dan karya seni. Bahasa, sebagaimana juga budaya, merupakan bagian tak terpisahkan dari diri manusia sehingga banyak orang cenderung menganggapnya diwariskan secara genetis. Ketika seseorang berusaha berkomunikasi dengan orang-orang yang berbeda budaya, dan menyesuaikan perbedaan-perbedaannya, membuktikan bahwa budaya itu dipelajari.

\subsection{Jenis Kebudayaan}

Kebudayaan dapat dibagi menjadi 3 macam dilihat dari keadaan jenis-jenisnya:

1. Hidup kebatinan manusia, yaitu sesuatu yang menimbulkan tertib damainya hidup masyarakat dengan adat-istiadatnya, pemerintahan negeri, agama atau ilmu kebatinan.

2. Angan-angan manusia, yaitu sesuatu yang dapat menimbulkan keluhuran bahasa, kesastraan dan kesusilaan.

3. Kepandaian manusia, yaitu sesuatu yang menimbulkan macam-macam kepandaian tentang perusahaan tanah, perniagaan, kerajinan, pelayaran, hubungan lalu-lintas, kesenian yang berjenis-jenis semuanya bersifat indah (Ki Hajar Dewantara; 1994).

\subsubsection{Kebudayaan berdasarkan wujudnya} Menurut J.J. Hoenigman, wujud kebudayaan dibedakan menjadi tiga, yaitu:

\section{Gagasan (Wujud ideal)}

Wujud ideal kebudayaan adalah kebudayaan yang berbentuk kumpulan ideide, gagasan, nilai-nilai, norma-norma, peraturan, dan sebagainya yang sifatnya abstrak tidak dapat diraba atau disentuh. Wujud kebudayaan ini terletak dalam kepala-kepala atau di alam pemikiran warga masyarakat..

2. Aktivitas (tindakan) 
Aktivitas adalah wujud kebudayaan sebagai suatu tindakan berpola dari manusia dalam masyarakat itu. Wujud ini sering pula disebut dengan sistem sosial.

\section{Artefak (karya)}

Artefak adalah wujud kebudayaan fisik yang berupa hasil dari aktivitas, perbuatan, dan karya semua manusia dalam masyarakat berupa benda-benda atau halhal yang dapat diraba, dilihat, dan didokumentasikan. Sifatnya paling konkret diantara ketiga wujud kebudayaan. Dalam kenyataan kehidupan bermasyarakat, antara wujud kebudayaan yang satu tidak bisa dipisahkan dari wujud kebudayaan yang lain. Sebagai contoh: wujud kebudayaan ideal mengatur dan memberi arah kepada tindakan (aktivitas) dan karya (artefak) manusia.

\subsection{Pengertian Edukasi}

Edukasi adalah proses pembelajaran yanag bertujuan untuk mengembangkan potensi diri pada peserta didik dan mewujudkan proses pembelajaran yang lebih baik. Edukasi ini bertujuan untuk mengembangkan kepribadian, kecerdasan dan mendidik peserta untuk memiliki akhlak mulia, mampu mengendalikan diri dan memiliki keterampilan. Edukasi lebih dikenal dan diucapkan dengan kata pendidikan atau edukasi adalah upaya manusia dewasa membimbing manusia yang belum dewasa kepada kedewasaan. Edukasi ialah usaha menolong anak untuk melaksanakan tugastugas hidupnya, agar bisa mandiri, akilbalik, dan bertanggung jawab secara susila. Edukasi adalah usaha mencapai penentuandiri-susila dan tanggung jawab. (M.J Langeveld, 1905).

\subsection{Multimedia}

Panduan untuk multimedia harus dimulai dengan definisi atau pengertian multimedia. Dalam industri elektronika, multimedia adalah kombinasi dari komputer dan video (Rosch,1996) atau multimedia secara umum merupakan kombinasi tiga elemen yaitu suara, gambar, dan teks (Mc Cormick,1996) atau multimedia adalah kombinasi dari paling sedikit dua media input dan output dari data, media ini dapat berupa audio (suara, musik), animasi, video, teks, grafik dan gambar (Turban dkk, 2002) atau multimedia merupakan alat yang menciptakan presentasi yang dinamis dan interaktif yang mengkombinasikan teks, grafik, animasi, audio dan gambar video.
Definisi lain dari multimedia yaitu dengan menempatkannya dalam konteks, seperti yang dilakukan oleh (Hoftsteter, 2001). Multimedia adalah pemanfaatan komputer untuk membuat dan menggabungkan teks, grafik, audio, video dan animasi dengan menggabungkan link dan tool yang memungkinkan pemakai melakukan navigasi, berinteraksi, berkreasi dan berkomunikasi (Munir. 2012).

\subsection{Android}

Android adalah sistem operasi berbasis Linux yang dirancang untuk perangkat bergerak layar sentuh seperti telepon pintar dan komputer tablet. Android awalnya dikembangkan oleh Android, Inc dengan dukungan finansial Google, yang kemudian membelinya pada tahun 2005 .

\subsubsection{Sejarah Android}

Android adalah sistem operasi yang berbasis Linux untuk telepon seluler seperti telepon pintar dan komputer tablet. Android menyediakan platform terbuka bagi para pengembang untuk menciptakan aplikasi mereka sendiri untuk digunakan oleh bermacam peranti bergerak. Awalnya, Google Inc. membeli Android Inc., pendatang baru yang membuat peranti lunak untuk ponsel. Kemudian untuk mengembangkan Android, dibentuklah Open Handset Alliance, konsorsium dari 34 perusahaan peranti keras, peranti lunak, dan telekomunikasi, termasuk Google, HTC, Intel, Motorola, Qualcomm, TMobile, dan Nvidia.

Pada saat perilisan perdana Android, 5 November 2007, Android bersama Open Handset Alliance menyatakan mendukung pengembangan standar terbuka pada perangkat seluler. Di lain pihak, Google merilis kodekode Android di bawah lisensi Apache, sebuah lisensi perangkat lunak dan standar terbuka perangkat seluler.

\subsubsection{Perkembangan Android}

a. Android versi 1.1

Android memang diluncurkan pertama kali pada tahun 2007, namun sistem operasi ini mulai dirilis dan diterapkan ke berbagai gadget pada tanggal 9 Maret 2009 silam. Android versi 1.1 merupakan Android awal yang dimana versi ini baru memberikan sentuhan dibeberapa aplikasinya seperti sistem antar muka bagi pengguna (user interface) yang lebih baik, serta beberapa aplikasi yang lain.

b. Android versi 1.5 (Cupcake) 
Pada bulan Mei 2009 Android kembali mengalami perubahan versi. Android versi 1.1 kemudian disempurnakan dengan Android versi 1.5 atau yang dikenal sebagai Android Cupcake.

c. Android versi 1.6 (Donut)

Donut (versi 1.6) diluncurkan dalam tempo kurang dari 4 bulan semenjak peluncuran perdana Android Cupcake, yaitu pada bulan September 2009.

d. Android versi 2.0/2.1 (Eclair)

Masih ditahun yang sama, Android kembali merilis operating sistem versi terbarunya, yaitu Android versi 2.0/2.1 Eclair. Android Eclair diluncurkan oleh Google 3 bulan setelah peluncuran.

e. Android versi 2.2 (Froyo: Frozen Yoghurt) Butuh 5 bulan bagi Google untuk melakukan regenerasi dari Android Eclair versi sebelumnya ke versi Froyo Frozen Yoghurt. Pada tanggal 20 Mei 2010, Android versi 2.2 alias Android Froyo ini dirilis.

f. Android versi 2.3 (Gingerbread)

7 bulan kemudian Android kembali melakukan gebrakan dengan merilis kembali Android versi 2.3 atau yang dikenal sebagai Android Gingerbread.

g. Android versi 3.0/3.1 (Honeycomb)

Pada bulan Mei 2011 Android versi 3.0/3.1 atau Android Honeycom dirilis. Android Honeycomb merupakan sebuah sistem operasi Android yang tujuannya memang dikhususkan bagi penggunaan tablet berbasis Android.

h. Android versi 4.0 (ICS: Ice Cream Sandwich) Android ICS atau Ice Cream Sandwich juga dirilis pada tahun yang sama dengan Honeycomb, yaitu pada bulan Oktober 2011.

i. $\quad$ Android versi 4.1 (Jelly Bean)

Android Jelly Bean merupakan versi Android yang terbaru pada saat ini. Salah satu gadget yang menggunakan sistem operasi Jelly Bean adalah Google Nexus 7 yang diprakarsai oleh ASUS, vendor asal Taiwan yang juga menjadi teman satu kampung halaman dengan Acer.

j. $\quad$ Android versi 4.4 (Kit Kat)

Kehadiran android kitkat merupakan pelucuran produk OS anyar yang dilucurkan pada 4 september 2013, sebelumnya banyak kabar beredar jikalau android akan meluncurkan OS baru yang bernama Android Key Lime Pie namun setelah di analisa tidak sesuai dengan ejaan orang umum, sehingga namanya diganti dengan OS Android KitKat yang sebagian besar orang sudah familiar dengan itu.

k. Android versi 5.0.2 (Lollipop)

Android Lollipop merupakan keberadaan OS Android yang memang saat ini sudah menjadi trend baru di industri smartphone, hal ini tak lepas dari keunikan dan kelebihan yang banyak di miliki dari OS tersebut. Kehadiran android versi ini amat di nanti oleh sekian banyak orang karna diharapkan sistem operasi Lollipop ini bias lebih baik dibandingkan versi-versi sebelumnya.

1. Android versi 6.0 (Marshmallow)

Android 6.0 Marshmallow adalah versi dari sistem operasi mobile Android. Pertama kali diperkenalkan Mei 2015 di Google I / O di bawah kode nama Android M, secara resmi dirilis pada Oktober 2015. Android Marshmallow memperkenalkan model izin aplikasi didesain ulang sekarang ada hanya delapan kategori izin, dan aplikasi yang tidak lagi secara otomatis diberikan semua hak akses mereka ditentukan pada waktu instalasi.

\subsection{Android SDK (Software Development Kit)}

Android SDK adalah tools API (Application Programming Interface) yang diperlukan untuk memulai mengembangkan aplikasi pada platform Android menggunakan bahasa pemrograman Java.

Beberapa fitur Android yang penting adalah sebagai berikut :

a. Framework aplikasi yang mendukung penggantian komponen dan reusable.

b. DVM dioptimalkan untuk perangkat mobile.

c. Integrated browser berdasarkan engine open source WebKit.

d. Grafis yang dioptimalkan dan didukung oleh libraries grafis 2D, grafis 3D berdasarkan spesifikasi Open GL ES 1.O.

e. SQLite untuk penyimpanan data.

f. Dukungan untuk audio, video dan gambar.

g. Bluetooth, Edge, 3G, Wifi.

h. Kamera, GPS, kompas dan accelerometer.

Lingkungan development yang lengkap dan kaya termasuk perangkat emulator, tools untuk debugging, profil dan kinerja memori serta plugins untuk IDE Eclipse.

\subsection{Eclipse}

Eclipse adalah sebuah IDE (Integrated Development Environment) untuk mengembangkan perangkat lunak dan dapat dijalankan di semua platform (platformindependent). 


\subsection{SQLite}

SQLite merupakan sebuah system management basis data relasional yang bersifat ACID - compliant dan memiliki ukuran pustaka kode yang relatif kecil, ditulis dalam bahasa C. SQLite merupakan proyek yang bersifat public domain yang dikerjakan oleh D. Richard Hipp.

SQLite mengimplementasikan hampir seluruh elemen-elemen standar yang berlaku pada $S Q L-92$, termasuk transaksi yang bersifat atomic, konsistensi basis data, isolasi, dan durabilitas (dalam bahasa inggris lebih sering disebut ACID), trigger, dan kueri-kueri yang kompleks.

\subsection{ADB (Android Debug Bridge)}

ADB adalah alat serbaguna yang bisa mengendalikan perangkat Android (emulator) yang terhubung dengan komputer. Dengan ADB kita bisa menggunakan smartphone Android kita untuk melakukan pengujian aplikasi.

\subsection{ADT(Android Developer Tools)}

Safaat (2012: 6) juga memaparkan bahwa Android Development Tools (ADT) adalah plug-in yang didesain untuk IDE Eclipse yang memberi kita kemudahan dalam mengembangkan aplikasi Android dengan menggunakan IDE Eclipse.

\subsection{JDK (Java Development Kit)}

Menurut DeCoster (2012), Java adalah sebuah teknologi yang diperkenalkan oleh Sun Microsysytems pada pertengahan tahun 1990. Menurut definisi Sun, Java adalah nama untuk sekumpulan teknologi untuk membuat dan menjalankan perangkat lunak pada computer standalone ataupun pada lingkungan jaringan. Untuk membuat program Java dibutuhkan kompiler dan interpreter untuk program Java berbentuk Java Development Kit (JDK) yang diproduksi oleh Sun Microsystems. Sebelum memulai instalasi Android SDK, terlebih dahulu kita harus melakukan instalasi JDK dikomputer. JDK yang kami gunakan untuk dapat mengompilasi aplikasi Android yang kami rancang ini adalah Java SE Development Kit 8.

2.12 UML

UML (Unified Modelling Language) adalah salah satu alat bantu yang sangat handal di dunia pengembangan sistem yang berorientasi obyek. Hal ini disebabkan karena UML menyediakan bahasa pemodelan visual yang memungkinkan bagi pengembangan sistem untuk membuat cetak biru atas visi mereka dalam bentuk yang baku, mudah dimengerti serta dilengkapi dengan mekanisme yang efektif untuk berbagi dan mengkomunikasikan rancangan mereka dengan yang lain.

\subsubsection{Use Case Diagram}

Munawar (2005 : 64) menyatakan bahwa use case adalah deskripsi fungsi dari sebuah sistem dari perspektif pungguna. Use case bekerja dengan cara deskripsikan tipikal interaksi pada antar user (pengguna) sebuah sistem dengan sistemnya sendiri melalui sebuah cerita bagaimana sebuah sistem dipakai.

\subsubsection{Activity diagram}

Activity diagram menurut Munawar (2005: 109) adalah teknik untuk mendeskripsikan logika prosedural, proses bisnis dan aliran kerja dalam banyak kasus. Activity diagram mempunyai peran seperti halnya flowchart, akan tetapi perbedaannya dengan flowchart adalah activity diagram bisa mendukung perilaku paralel sedangkan flowchart tidak bisa.

\subsubsection{Diagram Class}

Class adalah sebuah spesifikasi yang jika diinstansiasi akan menghasilkan sebuah objek dan merupakan inti dari pengembangan dan desain berorientasi objek.

\subsubsection{Diagram Sequence}

Diagram sequence merupakan salah satu yang menjelaskan bagaimana suatu operasi itu dilakukan message (pesan) apa yang dikirim dan kapan pelaksanaannya.

\subsection{Metode Luther}

Dalam tahap perancangan aplikasi dan pembuatan aplikasi, Menurut Luther(1994) terdapat 6 tahap yaitu:

1. Concept (Perancangan Konsep)

2.Design (Pendesainan)

3.Material Collecting (Pengumpulan Bahan dan Materi)

4.Assembly (Pembuatan/pengkodean)

5.Testing (Pengujian)

6.Distribution (Pendistribusian)

Keenam tahap ini tidak harus berurutan dalam praktiknya, tahap-tahap tersebut bisa dapat bertukar posisi tergantung kebutuhan. Meskipun begitu, tahap Concept memang harus menjadi hal pertama yang di kerjakan.

Penjelasan rinci tentang proses diatas adalah sebagai berikut,

\section{Concept}


Tahap concept (konsep) adalah tahap untuk menentukan tujuan dan siapa pengguna program (identifikasi audience). Selain itu menentukan macam aplikasi (presentasi, interaktif, dll) dan tujuan aplikasi (hiburan, pelatihan, pembelajaran, dll).

2. Design

Design (perancangan) adalah tahap membuat spesifikasi mengenai arsitektur program, gaya, tampilan dan kebutuhan material/bahan untuk program.

\section{Material Collecting}

Material Collecting adalah tahap dimana pengumpulan bahan yang sesuai dengan kebutuhan dilakukan. Tahap ini dapat dikerjakan paralel dengan tahap assembly. Pada beberap kasus, tahap Material Collecting dan tahap Assembly akan dikerjakan secara linear tidak paralel.

4. Assembly

Tahap assembly (pembuatan) adalah tahap dimana semua objek atau bahan multimedia dibuat. Pembuatan aplikasi didasarkan pada tahap design.

5. Testing

Dilakukan setelah selesai tahap pembuatan (assembly) dengan menjalankan aplikasi/program dan dilihat apakah ada kesalahan atau tidak. Tahap ini disebut juga sebagai tahap pengujian alpha (alpha test) dimana pengujian dilakukan oleh pembuat atau lingkungan pembuatnya sendiri.

\section{Distribution}

Tahapan dimana aplikasi disimpan dalam suatu media penyimpanan. Pada tahap ini jika media penyimpanan tidak cukup untuk menampung aplikasinya, maka dilakukan kompresi terhadap aplikasi tersebut.

\subsection{Black Box Testing}

Pengujian Black-Box merupakan metode yang menguji perangkat lunak dari segi spesifikasi fungsional tanpa menguji desain dan kode program.

\section{ANALISIS DAN PERANCANGAN}

Dalam proses perancangan suatu aplikasi diperlukan analisa konsep yang tepat agar proses pembuatan dapat berjalan dengan baik dan sistem yang dibuat sesuai dengan yang diinginkan. Setelah analisis dilakukan perlu dilakukan perancangan aplikasi yang bertujuan untuk memberikan gambaran bagaimana jalannya aplikasi tersebut. Selain itu, perancangan juga dapat mempermudah programmer dalam mengimplementasikan aplikasi tersebut

\subsection{Konsep}

Dalam membuat sebuah Aplikasi Edukasi Toba Samosir tentunya harus diawali dengan proses pembuatan konsep. Pada tahap konsep ini berisi mengenai analisa permasalahan, analisa kebutuhan, deskripsi umum sistem dan alur kerja sistem.

Media informasi wisata pada saat ini semakin berkembang, namun perkembangan tersebut tidak diikuti dengan pemanfaatan media tersebut. Oleh karena itu informasi wisata ini memanfaatkan kemajuan teknologi untuk mempermudah user dalam mencari informasi wisata terutama pada ruang lingkup budaya toba samosir yang terpopuler. Media informasi wisata pada umumnya memanfaatkan media berupa website dan iklan di televisi. Dalam proses pembuatan aplikasi informasi budaya toba samosir ini memang tidak semudah media website maupun iklan di televisi tetapi aplikasi ini lebih praktis dan efisien jika dibandingkan dengan kedua media sebelumnya. Oleh karena itu penulis melakukan analisa permasalahan apa saja dalam membuat aplikasi edukasi toba samosir pada telepon seluler berbasis android.

1. Data apa saja yang diperlukan dalam proses pembuatan aplikasi ?

2. Bagaimana cara memberikan suara pada halaman wisata dan budaya ?

3. Bagaimana cara merancang navigasi yang mudah digunakan dan antarmuka aplikasi yang menarik pada penggunanya ?

\subsubsection{Analisa Kebutuhan}

Perangkat keras yang digunakan penulis untuk melakukan penelitian ini adalah satu set laptop dengan spesifikasi :

1. Processor : Intel ${ }^{\circledR}$ Core ${ }^{\mathrm{TM}}$ i5-4210U CPU @ $1.70 \mathrm{GHz}$

2. Memory : 4.00GB RAM

3. Harddisk Drive : $750 \mathrm{~GB}$

4. Video Graphics Adapter (VGA) : Intel® HD Graphics Family

5. Keyboard: PS/2 devices

Sedangkan perangkat lunak yang digunakan penulis dalam penelitian ini adalah :

1. Windows 8.1Pro 64-bit sebagai sistem operasi.

2. Eclipse sebagai developer aplikasi.

3. Adobe Photoshop CS3 untuk membuat button pada aplikasi.

4. Android SDK sebagai compiler untuk membuat Android Package (APK file). 


\subsection{Perancangan Sistem}

Perancangan sistem merupakan gambaran atau sketsa dan pembuatan dari beberapa tahap yang terpisah kedalam satu kesatuan yang utuh. Tujuan dari perancangan aplikasi adalah untuk memberikan gambaran kepada pengguna tentang aplikasi yang akan dibuat serta memberi ilustrasi atau rekayasa aplikasi yang lengkap untuk diimplementasikan ke dalam program tersebut. 3.2.1 Pemodelan Use Case Diagram

Diagram use case digunakan untuk menjelaskan dan menggambarkan sistem dan perilaku pengguna terhadap sistem itu sendiri. Diagram use case lebih menekankan apa yang akan diperbuat oleh sistem dan bukan menekankan bagaimana sistem tersebut bertindak.

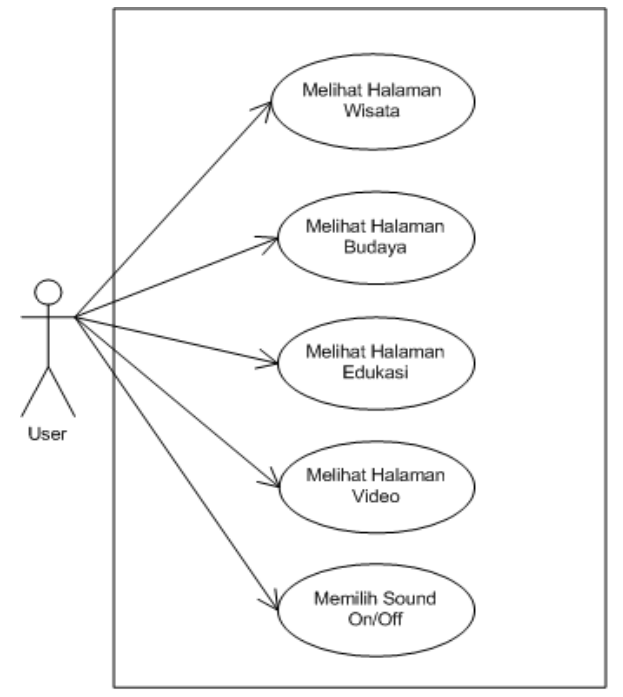

Gambar 1. Gambar Use Case Diagram

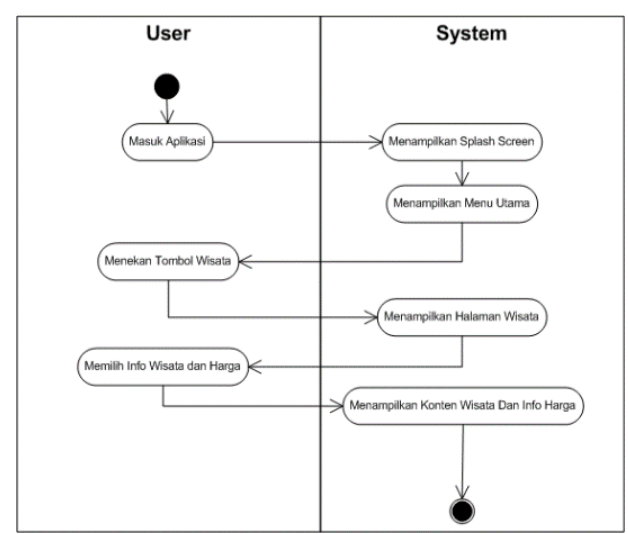

Gambar 2. Activity Diagram Halaman Wisata

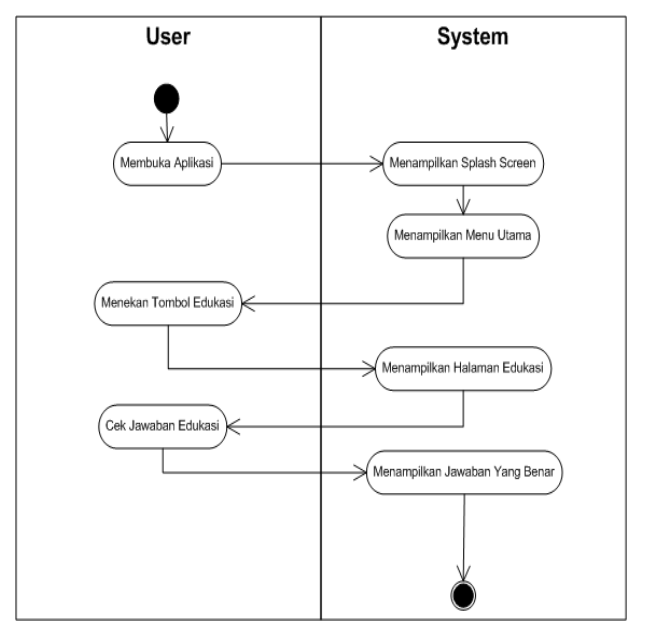

Gambar 3. Activity Diagram Halaman Edukasi

\subsubsection{Perancangan Aplikasi}

Perancangan adalah penggambaran, perencanaan dan pembuatan sketsa atau pengaturan dari beberapa elemen yang terpisah kedalam satu kesatuan yang utuh. Perancangan sistem dapat dirancang dalam bentuk bagan alir sistem (system flowchart), yang merupakan alat bentuk grafik yang dapat digunakan untuk menunjukan urutan-urutan proses dari sistem (Syifaun Nafisah, 2003:2).

\section{IMPLEMENTASI DAN PENGUJIAN}

Pada bab ini akan dibahas mengenai implementasi dan pengujian, setelah sebelumnya dilakukan analisa dan perancangan terhadap Aplikasi Game Labirin. Implementasi merupakan tahap realisasi dari rancangan sistem ke dalam struktur pemrograman dan menghasilkan aplikasi yang siap untuk di uji dan dioperasikan oleh target pengguna. Pembahasan tersebut akan dijelaskan pada subbab berikut ini.

\subsection{Implementasi Aplikasi}

Setelah melakukan analisa dan perancangan aplikasi langkah selanjutnya adalah pengkodean (implementasi) dan pengujian. Implementasi merupakan desain (perancangan) aplikasi dengan kode-kode tertentu yang dapat dimengereti oleh mesin dengan spesifikasi perangkat lunak (software) dan perangkat keras (Hardware) yang digunakan.

\subsection{Perangkat Pendukung Pengembangan}

Untuk melaksanakan penelitian ini tentunya membutuhkan alat pendukung berupa perngkat keras dan perangkat lunak, alat-alat yang digunakan dijelaskan sebagai berikut:

$$
\text { - Laptop }
$$

1. Microsoft Windows 8.1 Single Languange 64 Bit 
2. Eclipse Developer Tools Version: v21.1.0569685

3. Android Developer Tools (ADT)

4. Java Development Kit (Versi 8)

5. SQLite

6. Android SDK

7. BlueStack Agent (0.9.6.4092) Android Versi 4.4.4(Kit-Kat)

- $\quad$ Ponsel Android

Android 5.0 (Lollipop) sebagai sistem operasi.

\subsection{Implementasi Basis Data}

Database untuk aplikasi edukasi toba samosir ini menggunakan SQLite yang bernama Database Adapter.

\subsubsection{Tabel Informasi Samosir}

Tabel wisata digunakan untuk menempatkan wisata yang akan dipilih user.

Tabel 1. Struktur Tabel Informasi Samosir

\begin{tabular}{|l|l|l|l|}
\hline No & Nama & Tipe Data & Key \\
\hline 1 & ID & INT & $\begin{array}{l}\text { Primary } \\
\text { Key }\end{array}$ \\
\hline 2 & Kuliner & Varchar(50) & \\
\hline 3 & Nama & Varchar(50) & \\
\hline 4 & Image & Varchar(50) & \\
\hline 5 & Keterangan & TEXT & \\
\hline
\end{tabular}

\subsection{Implementasi Antarmuka Aplikasi}

4.4.1 Antarmuka Splash Screen

Di sini akan menampilkan splash screen selama 5 detik sebelum masuk ke menu utama.

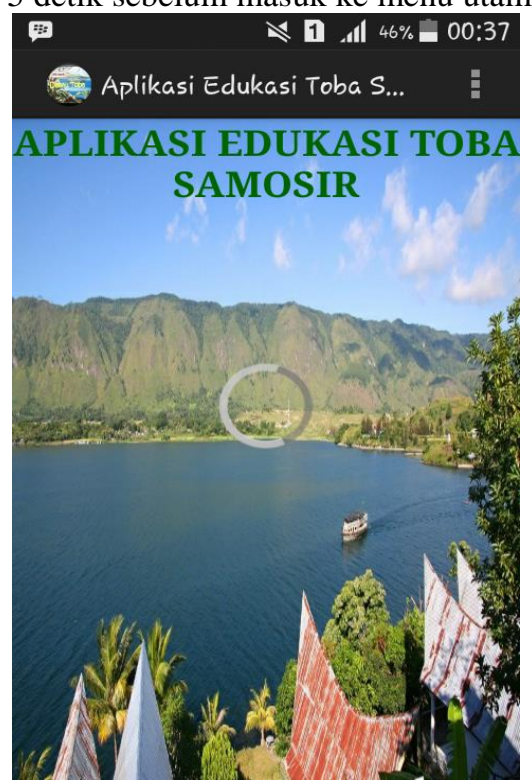

Gambar 4. Antarmuka SplashScreen

\subsubsection{Antarmuka Halaman Wisata}

Harni Kusniyati: Aplikasi Edukasi Budaya....
Layout wisata ini user bisa memilih informasi wisata serta informasi harga yang ingin diketahui.

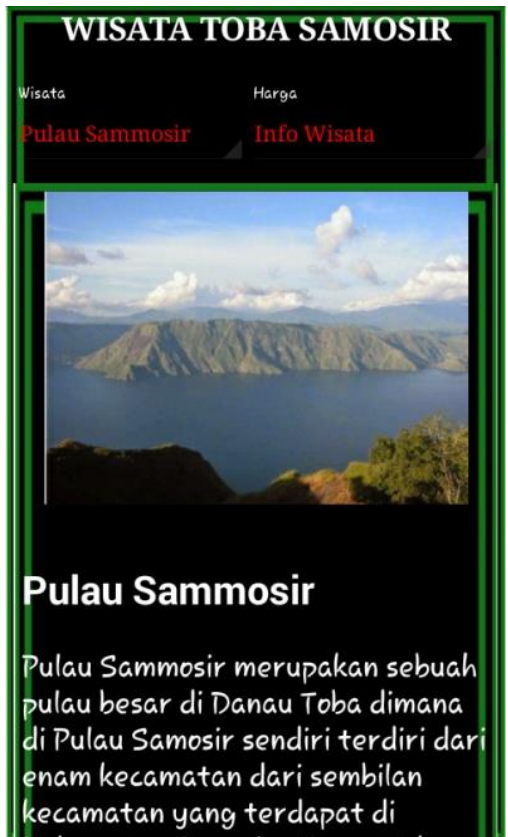

Gambar 5. Antarmuka Halaman Wisata

\subsection{Pengujian Aplikasi}

Pengujian sistem dilakukan sebagai verifikasi atas sistem yang telah dibangun. Hal ini dimaksudkan untuk mengetahui kemungkinan terjadinya kesalahan dan untuk memastikan fungsi- fungsi pada sistem berjalan dengan baik. Pengujian yang penulis lakukan menggunakan metode pengujian Black-box. Metode Black-box merupakan metode pengujian berdasarkan pada fungsionalitas perangkat lunak, serta bertujuan untuk menemukan kemungkinan kesalahan fungsi tertentu.

Tabel 2. Hasil Pengujian

\begin{tabular}{|l|l|l|l|l|}
\hline No & Skenario & Rencana & $\begin{array}{l}\text { Hasil yang } \\
\text { diharapkan }\end{array}$ & $\begin{array}{l}\text { Hasil } \\
\text { Penguj } \\
\text { ian }\end{array}$ \\
\hline 1. & $\begin{array}{l}\text { Button } \\
\text { Wisata }\end{array}$ & $\begin{array}{l}\text { Klik } \\
\text { button } \\
\text { Wisata }\end{array}$ & $\begin{array}{l}\text { Terbuka } \\
\text { layout } \\
\text { Wisata }\end{array}$ & $\begin{array}{l}\text { SUKS } \\
\text { ES }\end{array}$ \\
\hline 2. & $\begin{array}{l}\text { Select } \\
\text { Box } \\
\text { wisata }\end{array}$ & $\begin{array}{l}\text { Memilih } \\
\text { informasi } \\
\text { wisata }\end{array}$ & $\begin{array}{l}\text { Menampilk } \\
\text { an informasi } \\
\text { wisata }\end{array}$ & $\begin{array}{l}\text { SUKS } \\
\text { ES }\end{array}$ \\
\hline 3. & $\begin{array}{l}\text { Select } \\
\text { Box harga }\end{array}$ & $\begin{array}{l}\text { Memilih } \\
\text { info } \\
\text { harga }\end{array}$ & $\begin{array}{l}\text { Menampilk } \\
\text { an daftar } \\
\text { informasi } \\
\text { harga. }\end{array}$ & $\begin{array}{l}\text { SUKS } \\
\text { ES }\end{array}$ \\
\hline 4 & $\begin{array}{l}\text { Button } \\
\text { Budaya }\end{array}$ & $\begin{array}{l}\text { Klik } \\
\text { button } \\
\text { Budaya }\end{array}$ & $\begin{array}{l}\text { Terbuka } \\
\text { layout } \\
\text { Budaya }\end{array}$ & $\begin{array}{l}\text { SUKS } \\
\text { ES }\end{array}$ \\
\hline 5 & Select & Memilih & Menampilk & SUKS \\
\hline
\end{tabular}




\begin{tabular}{|l|l|l|l|l|}
\hline & $\begin{array}{l}\text { Box } \\
\text { Budaya }\end{array}$ & $\begin{array}{l}\text { informasi } \\
\text { budaya }\end{array}$ & $\begin{array}{l}\text { an informasi } \\
\text { budaya }\end{array}$ & ES \\
\hline 6 & $\begin{array}{l}\text { Button } \\
\text { Edukasi }\end{array}$ & $\begin{array}{l}\text { Klik } \\
\text { button } \\
\text { Edukasi }\end{array}$ & $\begin{array}{l}\text { Terbuka } \\
\text { layout } \\
\text { Edukasi }\end{array}$ & $\begin{array}{l}\text { SUKS } \\
\text { ES }\end{array}$ \\
\hline 7 & $\begin{array}{l}\text { Button } \\
\text { Video }\end{array}$ & $\begin{array}{l}\text { Klik } \\
\text { button } \\
\text { video }\end{array}$ & $\begin{array}{l}\text { Terbuka } \\
\text { layout video } \\
\text { dan } \\
\text { memutar } \\
\text { video }\end{array}$ & $\begin{array}{l}\text { SUKS } \\
\text { ES }\end{array}$ \\
\hline & & & & \\
\hline
\end{tabular}

\subsubsection{Distribusi}

Dalam memudahkan pengembang dan pengguna perangkat Android, Google menyediakan toko software online bagi aplikasi-aplikasi Android yang diberi nama Play Store. Dengan adanya aplikasi Play Store yang di-instal pada perangkat Android memungkinkan pengguna mencari dan mendownload aplikasi yang telah dikembangkan oleh pengembang aplikasi Android.

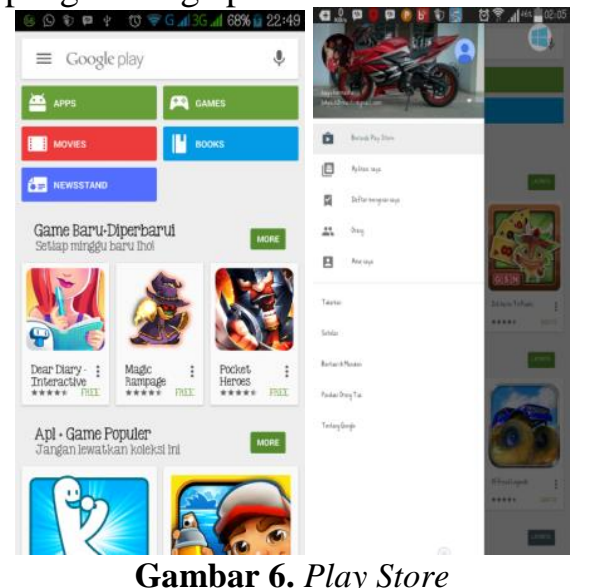

Hasil akhir dari aplikasi ini adalah file paket instalasi Android yaitu Aplikasi Edukasi Toba Samosir.apk. File ini dapat di distribusikan melalui layanan Play Store, sehingga setiap pengguna Android dapat meng-instal langsung melalui market.

\subsection{Kesimpulan}

Berdasarkan tahapan analisa, perancangan, implementasi dan pengujian yang telah dilakukan oleh penulis terhadap Aplikasi Edukasi Budaya Toba Samosir Berbasis Android, secara umum dapat diperoleh kesimpulan sebagai berikut :

1. Penelitian ini telah berhasil membangun aplikasi edukasi budaya toba samosir berbasis android dan sesuai dengan perancangan yang telah dilakukan.
2. Pembuatan aplikasi ini adalah upaya mempermudah mengakses informasi budaya toba samosir.

3. Aplikasi ini mengenalkan informasi mengenai budaya, wisata dan juga kesenian khas toba samosir kepada user agar dapat dipahami sebelum menuju lokasi yang akan dikunjungi.

\subsection{Saran}

Aplikasi yang dibuat ini tentunya masih banyak yang harus dikembangkan agar dapat meningkatkan kualitas dan kegunaannya. Saran untuk pengembangan aplikasi ini antara lain :

1. Pembaharuan user interface agar aplikasi ini lebih berwarna dan menarik lagi untuk digunakan.

2. Aplikasi edukasi budaya toba samosir ini tidak terbatas hanya pada platform android saja, melainkan dapat mendukung platform mobile maupun komputer lainnya. Sehingga penggunaan aplikasi edukasi budaya toba samosir tidak hanya sebatas menggunakan ponsel saja.

3. Penambahan lokasi wisata yang belum ada di daftar wisata toba samosir.

4. Penambahan video dan fitur-fitur baru yang menarik lagi bagi user.

\section{DAFTAR PUSTAKA}

[1] Bavota, Gabriele. 2015. The Impact of API Change and Fault Proneness on the User Ratings of Android Apps : http : search.ebcohost.com

[2] Cormick, Mc. 1996. Pengertian Multimedia Menurut Para Ahli : http://tiasopyan.blogspot.co.id/2015/02/pengertian -multimedia-menurut-para-ahli.html

[3] Dewantara, Ki Hajar. 1994. Pengertian Budaya Menurut Para Ahli: http://www.seputarpengetahuan.com/2015 /03/pengertian-budaya-menurut-para-ahlilengkap.html

[4] Decoster. 2012. Pengertian Java Development Kit : http://library.binus.ac.id

[5] Dimarzio, J. 2008. "Android ${ }^{\mathrm{TM}}$ A Programmer's Guide". The McGraw-Hill Companies.

[6] Hermawan. S, Stephanus. 2011. Mudah Membuat Aplikasi Android. Yogyakarta : ANDI.

[7] Hermanto, Bayu. 2015. Aplikasi Multimedia Pariwisata Laut Indonesia 
Berbasis Android. Jakarta. Universitas Mercu Buana.

[8] Hofster. 2001. Pengertian Multimedia Menurut Para Ahli : http://tiasopyan.blogspot.co.id/2015/02/pengertian -multimedia-menurut-para-ahli.html

[9] Jeehong, Kim. 2015. Static Dalvik Bytecode Optimization for Android Applications : http://dx.doi.org

[10] Kadir, Abdul. 2009. Dasar Perancangan dan Implementasi Database Relasional, Yogyakarta : ANDI.

[11] Kang-Wook, Kim. 2015. An Efficient Implementation of Key Frame Extraction and Sharing in Android for Wireless Video Sensor Network : http://search.ebcohost.com

[12] Langeveld, M.J. 1905. Pengertian Pendidikan Menurut Para Ahli : http://www.seputarpengetahuan.com/2015 /02/15-pengertian-pendidikan-menurutpara-ahli.html

[13] Mojica, Ruiz. 2014. Impact of Ad Libraries on Ratings of Android Mobile Apps : http://search.ebcohost.com

[14] Munawar. 2005. Pengertian Unified Modelling Languange : http://bacablogmaisar.blogspot.com/2013/ 06/v-behaviorurldefaultvmlo.html

[15] Munawar. 2005 : 64. Pengertian Use Case Diagram http://bacablogmaisar.blogspot.com/2013/ 06/v-behaviorurldefaultvmlo.html

[16] Munawar. 2005 : 109. Pengertian Activity Diagram http://bacablogmaisar.blogspot.com/2013/ 06/v-behaviorurldefaultvmlo.html

[17] Narendra Ragan Prabu (2012). Kumpulan Project Aplikasi Android Untuk Pemula.

[18] Nafisah, Syifaun. Perancangan Aplikasi : http://tugasakhiramik.blogspot.co.id/2013/ 03/pengertian-perancangan-aplikasi.html

[19] Post, Gerald V. 1999. Database Management Systems. Designing And Building Bussiness Applications. Singapore: The Mc Graw-Hill Companies.

[20] Rosch. 1996. Pengertian Multimedia Menurut Para Ahli : http://tiasopyan.blogspot.co.id/2015/02/pengertian -multimedia-menurut-para-ahli.html

[21] Safaat. 2012: 6. Pengertian Android Developer Tools

http://library.binus.ac.id
[22] Shalahuddin. 2011. Pengujian Balck Box Testing : http://elib.unikom.ac.id

[23] Sutopo. 2003. Penjelasan Metode Luther : http://iwanbinanto.com/2009/01/19/metod e-pengembangan-multimedia/

[24] Turban. 2002. Pengertian Multimedia Menurut Para Ahli : http://tiasopyan.blogspot.co.id/2015/02/pengertian -multimedia-menurut-para-ahli.html

[25] Udanor, C.N. 2016. Motivation for the Design and Implementation of SMS Slang Converter for Android Devices : http://search.ebcohost.com

[26] http://www.twoh.co/2013/androiddatabase-sqlite-tutorial-i-membuatdatabase-sqlite/ (diakses tanggal 1 Oktober 2015).

[27] http://www.indonesia.travel/sites/site/119 4/samosir (diakses tanggal 18 Desember 2015). 